\title{
O Papel das Instituições Académicas e Científicas em Tempos de Pandemia COVID-19: Nunca a Ciência Médica foi tão Importante para a Sobrevivência Humana

\author{
The Role of Academic and Scientific Institutions in Times of Pandemic \\ COVID-19: Never has Medical Science been so Important to Human \\ Survival
}

\section{Fausto J. Pinto (https://orcid.org/0000-0002-8034-4529)}

Palavras-chave: Academias e Institutos; Coronavírus; Infecção por Coronavírus; Investigação Biomédica; Pandemia

Keywords: Academies and Institutes; Biomedical Research; Coronavirus; Coronavirus Infection; Pandemics

Vivemos tempos inimagináveis há apenas uns meses atrás provocados por uma pandemia inesperada, que, de súbito, alterou todas as rotinas e todo o conforto que tínhamos como adquirido. Nunca as gerações actuais tiveram de enfrentar uma situação idêntica, em que o mundo, como um todo, foi, de repente, confrontado com um inimigo comum. Pelas suas características apanhou todos de surpresa, começando pelos governantes e decisores políticos que, duma forma algo descoordenada, reagiram das mais variadas formas a este enorme desafio. Tratando-se dum desafio com um enorme componente de Saúde Pública e, como tal, com uma matriz científica muito forte, seria natural que os Governos recorressem aos cientistas e às respectivas instituições académicas e universitárias, sedes do saber, para se aconselharem e tomarem as suas decisões usando as referências mais adequadas. $\mathrm{Na}$ realidade, o que se constatou foi uma variedade enorme de atitudes, com resultados ainda não totalmente claros, mas com alguma evidência que já se vai revelando. Na Alemanha, um exemplo no que se refere à baixa taxa de letalidade, apesar do número elevado de infectados, a chanceler Angela Merkel, uma cientista de formação, constituiu um painel de aconselhamento com 26 académicos de topo duma variedade de áreas, incluindo psicologia comportamental e ética. Outros países tiveram atitudes mais políticas do que científicas, o que pode

Diretor do Departamento do Coração e Vasos, CHULN, Lisboa; Portugal

Diretor, Faculdade de Medicina da Universidade de Lisboa, Portugal

Presidente, Centro Cardiovascular da Universidade de Lisboa (CCUL), Portugal

Presidente Eleito, World Heart Federation (WHF), Genebra, Suiça

https://revista.spmi.pt - DOI: 10.24950/rspmi/ COVID19/F.Pinto/ FMUL/S/2020 justificar alguns dos resultados catastróficos, de que talvez o exemplo dos EUA seja o mais trágico, com mais de 900000 infectados e 52000 óbitos (ao dia de 25.04.2020), tendo Nova lorque, só por si, mais de 270 mil casos e mais de 21 mil óbitos. ${ }^{1}$ Por outro lado, assistimos a estratégias iniciais que foram posteriormente totalmente revertidas, em função dos resultados, como é o caso do Reino Unido, que iniciou com uma estratégia assente naquilo que alguns epidemiologistas mais conservadores e tradicionais recomendam, que é a chamada imunidade de grupo. O problema desta estratégia é que dadas as características deste vírus e da forma como a doença que daí resulta se manifesta, com um número significativo de doentes com necessidade de internamento e de cuidados intensivos, é incompatível com uma estratégia de imunidade de grupo rápida, a não ser que a sociedade aceite o sacrifício de milhares dos seus cidadãos, em particular os mais idosos, mas não só, dado que nenhum grupo etário está imune. Hoje, por exemplo, o Reino Unido, mesmo tendo revertido rapidamente a sua política inicial de imunidade de grupo tem cerca 150 mil infectados e mais de 20 mil mortes, ou seja, uma taxa de letalidade de cerca de 13\%. A Suécia, outro exemplo de país que optou por uma política menos restritiva, tem hoje 18 mil infectados e 2200 óbitos, correspondendo a uma taxa de letalidade de 12\%. Apesar de tudo Portugal hoje tem 23392 infectados e 880 óbitos oficiais, correspondendo a uma taxa de letalidade de $3,7 \%,{ }^{1}$ ou seja se tivéssemos seguido as recomendações de alguns epidemiologistas oficiais, pertencendo, inclusive a comissões oficiais, como o famigerado Conselho Nacional de Saúde Pública, teríamos hoje, provavelmente um cenário não muito diferente dos outros, com mais de 2500 mortos e, muito possivelmente, um sistema de saúde estilhaçado, tanto mais que o nosso sistema de saúde tem fragilidades objectivas muito mais acentuadas do que outros países europeus. Basta citar os números de camas de cuidados intensivos no início desta crise para facilmente perceber o panorama real, ou seja, Portugal tinha 4,2 camas de cuidados intensivos por 100000 habitantes, ${ }^{2}$ versus 29,2 da Alemanha, 12,5 da Itália ou 9,7 da Espanha, que entraram em rotura, precisamente pela avalanche que tiveram de enfrentar. Algumas das implicações destes números só é possível serem percebidos na sua 
plenitude para quem conhece o que isto significa na prática, nomeadamente o drama de ter de decidir entre doentes para admitir ou não em cuidados intensivos, ou mesmo decisões de quem ventilar ou não. Este assunto foi de tal modo relevante que foram inclusive feitas guidelines para ajudar a tomar este tipo de decisões, com o mínimo de cobertura ética sobre algo que nenhum de nós médicos pensaria ter de fazer. ${ }^{3,4}$

O papel das instituições académicas, como as Universidades e das sociedades científicas é, pois, fundamental, constituindo, de facto, o repositório do conhecimento e da experiência que poderão e deverão ajudar os decisores políticos a encontrar as melhores soluções. Realço aqui o papel do Conselho de Escolas Médicas Portuguesas (CEMP) que, desde o início, pautou a sua postura como de intervenção cívica, tendo produzido várias recomendações, quase sempre, de início, contradizendo o que as autoridades de saúde tinham publicamente manifestado (ex., encerramento de escolas, uso de máscaras, abertura dos dados à comunidade científica, etc.) e, que, felizmente, mais tarde acabaram por ser reconhecidos e adaptados. ${ }^{5}$ As sociedades científicas também se têm multiplicado por desenvolver várias metodologias que possam ajudar quer os profissionais de saúde quer a própria população a lidar com esta pandemia. ${ }^{6-8}$

A situação actual é, assim, um dos melhores exemplos onde a cooperação aberta, independente, objectiva, entre a ciência e a política, podem atingir resultados que, de outra forma, jamais seria possível. Mas é muito importante que os decisores políticos percebam que a cumplicidade que necessitam numa situação como esta é a da verdade ou, melhor, objectividade, científica, mesmo que incómoda e não consentânea com o que seria politicamente "desejável". E esta é a dificuldade que políticos convencionais têm tido, com grande instinto político, mas, muitas vezes, zero instinto científico.

Numa altura em que se começa a preparar o day after, é cada vez mais importante reforçar o papel que o aconselhamento científico pode ter para ajudar a uma saída mais adequada e responsável da crise que vivemos. Este é, pois, um momento único em que o recurso aos melhores é a garantia de sucesso, sobretudo numa altura em que há muito pouca margem de manobra. A possibilidade dum segundo surto em Portugal é uma realidade cada vez mais previsível dada a pressa em "abrir" a sociedade, com o risco de atropelar as regras que até agora têm dado resultados que, embora não excepcionais, permitiram manter funcionante o nosso sistema de saúde. Esperemos que o bom senso prevaleça e as recomendações baseadas na melhor evidência científica sejam seguidas.

Nunca a ciência médica foi tão importante para a sobrevivência humana.

Responsabilidades Éticas

Conflitos de Interesse: Os autores declaram a inexistência de conflitos de interesse na realização do presente trabalho.

Fontes de Financiamento: Não existiram fontes externas de financiamento para a realização deste artigo.

Proveniência e Revisão por Pares: Comissionado; sem revisão externa por pares.

\section{Ethical Disclosures}

Conflicts of interest: The authors have no conflicts of interest to declare. Financing Support: This work has not received any contribution, grant or scholarship.

Confidentiality of Data: The authors declare that they have followed the protocols of their work center on the publication of data from patients.

Provenance and Peer Review: Commissioned; without externally peer reviewed.

C Autor (es) (ou seu (s) empregador (es)) 2019. Reutilização permitida de acordo com CC BY-NC. Nenhuma reutilização comercial.

C Author(s) (or their employer(s)) 2019. Re-use permitted under CC BYNC. No commercial re-use.

Correspondence/Correspondência: Fausto J. Pinto faustopinto@medicina.ulisboa.pt

Faculdade de Medicina da Universidade de Lisboa Aenida Prof. Egas Moniz, 1649-028, Lisboa, Portugal

Received/Recebido: 26/04/2020

Accepted/Aceite: 28/04/2020

Publicado / Published: 8 de Maio de 2020

\section{REFERÊNCIAS}

1. D-19 Dashboard by the Center for Systems Science and Engineering (CSSE) at Johns Hopkins University (JHU). [consultado 25/04/2020] Disponível em: https://www.arcgis.com/apps/opsdashboard/index.html\#/ bda7594740fd40299423467b48e9ecf6 Assessed 25.04.2020

2. Rhodes A, Ferdinande P, Flaatten H, Guidet B, Metnitz PG, Moreno RP. The variability of critical care bed numbers in Europe. Intensive Care Med. 2012;38:1647-53.

3. Società Italiana di Anestesia Analgesia Rianimazione e Terapia Intensiva. Clinical ethics recommendations for the allocation of intensive care treatments, in exceptional, resource-limited circumstances [consultado 25/04/2020] Disponível em: http://www .siaarti.it/SiteAssets/News/ COVID19\%20\%20documenti\%20SIAARTI/SIAARTI\%20-\%20Covid19\%20-\%20Clinical\%20Ethics\%20Reccomendations.pdf).

4. Rosenbaum L. Facing Covid-19 in Italy - Ethics, Logistics, and Therapeutics on the Epidemic's Front Line. New Engl J Med. 2020 《 in press). Doi: 10.1056/NEJMp2005492

5. Conselho das Escolas Médicas Portuguesas [consultado 25/04/2020] Disponível em: http:// www.cemp.pt

6. Moraes de Oliveira G, Pinto FJ. COVID-19. A matter close to the heart. Int J Cardiovasc Sci. 2020 (in press). doi:10.36660/ijcs.20200057

7. Thienemann F, Pinto F, Grobbee DE, Boehm M, Bazargani N, Ge J, et al.. World Heart Federation Briefing on Prevention: Coronavirus Disease 2019 (COVID-19) in Low-Income Countries. Global Heart 2020;15:31. DOI: http://doi.org/10.5334/gh.778

8. European Society of Cardiology. [consultado 25/04/2020] Disponível em: https://www.escardio.org/Education/COVID-19-and-Cardiology/ESC-COVID-19-Guidance 